\title{
A HYBRID MCDM MODEL FOR SUPPLIER SELECTION IN SUPPLY CHAIN
}

\section{SANATAN RATNA, ASHISH GOSWAMI, KUMAR ANAND,}

\author{
ANAND KR. RAI \& AKASH YADAV
}

Department of Mechanical Engineering, ASET, Amity University, Noida, Uttar Pradesh, India

\begin{abstract}
Decision makers in SMEs across the world are in dilemma as a lot of suppliers with varying suitability are available in the market due to globalization and the liberalization of the Indian economy. The decision needs to be taken about the selection of the best supplier while keeping into account the various degrees of variations in the different criteria. This needs to be done to form an agile manufacturing environment. The current research work deals with the selection of the supplier based on six criteria among twenty-five suppliers. In order to achieve this, a hybrid MCDM model which consists of Grey Relational Analysis (GRA), Analytical Hierarchy Process (AHP) and Technique for Order Performance by Similarity to Ideal Solution (TOPSIS). GRA is used to shortlist the most important criteria among a number of criteria available. AHP is used to give weightage to the various selected criteria. At the end, the TOPSIS method is used to select the best supplier among the available twenty-five suppliers. The hybrid GRAPH-TOP model hence developed is used to analyze the supply chain management of an SME (forging industry) in Delhi NCR.

KEYWORDS: SME, MCDM, AHP, GRA, TOPSIS, Agile manufacturing environment \& Supply Chain Management
\end{abstract}

Received: Jan 22, 2019; Accepted: Feb 12, 2019; Published: Apr 13, 2019; Paper Id.: IJMPERDJUN201915

\section{INTRODUCTION}

Decision makers in SMEs across the world are spoilt for choice as the number of alternatives lying in front of them is vast. The decision needs to be taken about the selection of the best supplier while keeping into account the various degrees of variations in the different criteria. The current research work deals with the selection of the supplier based on six criteria among twenty-five suppliers. In order to achieve this, a hybrid MCDM model which consists of Grey Relational Analysis (GRA), Analytical Hierarchy Process (AHP) and Technique for Order Performance by Similarity to Ideal Solution (TOPSIS). GRA is used to shortlist the most important criteria among a number of criteria available. AHP is used to give weightage to the various selected criteria. At the end, the TOPSIS method is used to select the best supplier among the available twenty-five suppliers. The hybrid GRAPH-TOP model hence developed is used to analyze the supply chain management of an SME (forging industry) in Delhi NCR.

\section{METHODOLOGY}

The proposed methodology consists of ant integrated MCDM approach combining GRA, AHP \&TOPSIS. The grey system theory was developed by Deng Julong of China in the year 1982. The concept of Grey system is basically a representation of an incomplete or uncertain information system as the grey color lies between black (no information) \& white (all information). The method can convert a multi-response problem into a single response optimization problem by finding grey relation grades (GRG). AHP has been proved as a simple yet effective tool for multi-criteria decision making with plenty of applications reported in the fields of management science, 
industrial engineering, social science, etc. the philosophy behind AHP is to use the perception of decision maker or a group of decision-makers to prioritize various components or criteria which when combined lead to a clear numerical value for each solution. The decision makers can make pairwise comparisons of these criteria towards fulfilling the goal more easily. Hence, AHP is used for finding the weightage by first decomposing the problem into criteria and sub-criteria, which affect the goal of the multi criteria problem. The final selection of the supplier is done by using the TOPSIS technique. It is an acronym for the technique for order preference by similarity to an ideal solution. As the name suggests, the basis of this tool is to find the solution for multi-criteria problem, which is nearest to the ideal solution.

The criteria used for supplier selection in SCM are listed below.

C1- Commitment to DeliverySchedule;C2- An ISO 9000 Certified Supplier ; C3- Past Supply Record ;

C4- Supply Capacity of Supplier;C5- Packing Done to the Raw Material by the Supplier;

C6- Geographical Position of the Supplier

A list of criteria is shown above with which the questionnaire for taking a survey from industry experts is prepared. Survey values from 25 industry experts (R1,R2,R3,R4 ...R25) who are involved in supplier selection is shown in table 1.

Table 1: Survey Values from 10 Industry Experts who are Involved in Supplier Selection

\begin{tabular}{|c|c|c|c|c|c|c|}
\hline & C1 & C2 & C3 & C4 & C5 & C6 \\
\hline R1 & 5 & 4 & 4 & 4 & 3 & 3 \\
\hline R2 & 5 & 5 & 3 & 3 & 2 & 4 \\
\hline R3 & 4 & 5 & 3 & 3 & 4 & 4 \\
\hline R4 & 3 & 5 & 5 & 3 & 4 & 2 \\
\hline R5 & 5 & 3 & 3 & 3 & 5 & 4 \\
\hline R6 & 4 & 4 & 3 & 4 & 4 & 2 \\
\hline R7 & 5 & 4 & 4 & 4 & 3 & 3 \\
\hline R8 & 3 & 3 & 4 & 3 & 3 & 3 \\
\hline R9 & 5 & 4 & 2 & 3 & 2 & 3 \\
\hline R10 & 4 & 4 & 4 & 3 & 3 & 5 \\
\hline R11 & 5 & 4 & 5 & 5 & 4 & 5 \\
\hline R12 & 4 & 5 & 5 & 4 & 5 & 5 \\
\hline R13 & 5 & 5 & 4 & 4 & 4 & 4 \\
\hline R14 & 5 & 5 & 5 & 5 & 4 & 4 \\
\hline R15 & 4 & 4 & 4 & 5 & 5 & 5 \\
\hline R16 & 5 & 5 & 5 & 4 & 4 & 4 \\
\hline R17 & 4 & 5 & 5 & 4 & 4 & 5 \\
\hline R18 & 5 & 5 & 4 & 3 & 3 & 5 \\
\hline R19 & 5 & 5 & 3 & 3 & 2 & 3 \\
\hline R20 & 5 & 3 & 2 & 5 & 4 & 4 \\
\hline R21 & 5 & 4 & 4 & 4 & 5 & 4 \\
\hline R22 & 5 & 5 & 5 & 5 & 4 & 4 \\
\hline R23 & 5 & 5 & 4 & 4 & 4 & 4 \\
\hline R24 & 5 & 4 & 4 & 5 & 5 & 5 \\
\hline R25 & 5 & 5 & 4 & 4 & 3 & 3 \\
\hline
\end{tabular}

The table 2 below sows the difference with reference sequence values. 
Table 2: Difference with Reference Sequence Values

\begin{tabular}{|c|c|c|c|c|c|c|}
\hline & C1 & C2 & C3 & C4 & C5 & C6 \\
\hline R1 & 0 & 1 & 1 & 1 & 2 & 2 \\
\hline R2 & 0 & 0 & 2 & 2 & 3 & 1 \\
\hline R3 & 1 & 0 & 2 & 2 & 1 & 1 \\
\hline R4 & 2 & 0 & 0 & 2 & 1 & 3 \\
\hline R5 & 0 & 2 & 2 & 2 & 0 & 1 \\
\hline R6 & 1 & 1 & 2 & 1 & 1 & 3 \\
\hline R7 & 0 & 1 & 1 & 1 & 2 & 2 \\
\hline R8 & 2 & 2 & 1 & 2 & 2 & 2 \\
\hline R9 & 0 & 1 & 3 & 2 & 3 & 2 \\
\hline R10 & 1 & 1 & 1 & 2 & 2 & 0 \\
\hline R11 & 0 & 1 & 0 & 0 & 1 & 0 \\
\hline R12 & 1 & 0 & 0 & 1 & 0 & 0 \\
\hline R13 & 0 & 0 & 1 & 1 & 1 & 1 \\
\hline R14 & 0 & 0 & 0 & 0 & 1 & 1 \\
\hline R15 & 1 & 1 & 1 & 0 & 0 & 0 \\
\hline R16 & 0 & 0 & 0 & 1 & 1 & 1 \\
\hline R17 & 1 & 0 & 0 & 1 & 1 & 0 \\
\hline R18 & 0 & 0 & 1 & 2 & 2 & 0 \\
\hline R19 & 0 & 0 & 2 & 2 & 3 & 2 \\
\hline R20 & 0 & 2 & 3 & 0 & 1 & 1 \\
\hline R21 & 0 & 1 & 1 & 1 & 0 & 1 \\
\hline R22 & 0 & 0 & 0 & 0 & 1 & 1 \\
\hline R23 & 0 & 0 & 1 & 1 & 1 & 1 \\
\hline R24 & 0 & 1 & 1 & 0 & 0 & 0 \\
\hline R25 & 0 & 0 & 1 & 1 & 2 & 2 \\
\hline
\end{tabular}

The grey relational coefficient (GRC)is calculated now using the equation (1) below.

$\xi i(K)=\frac{(\Delta \min .+p \Delta \max )}{(\Delta X i(K)+p \Delta \max )}$

Here " $\mathrm{p}$ " is the distinguishing factor and is taken as 0.50 . The tenacity of the peculiar coefficient is to increase/decrease the range of the GRC. Table 3 below shows the calculated grey relational grades.

Table 3: Calculated Grey Relational Coefficients

\begin{tabular}{|c|c|c|c|c|c|c|}
\hline Responses from & C1 & C2 & C3 & C4 & C5 & C6 \\
\hline R1 & 1 & 0.5 & 0.6 & 0.5 & 0.428571 & 0.428571 \\
\hline R2 & 1 & 1 & 0.428571429 & 0.333333333 & 0.333333 & 0.6 \\
\hline R3 & 0.5 & 1 & 0.428571429 & 0.333333333 & 0.6 & 0.6 \\
\hline R4 & 0.333333333 & 1 & 1 & 0.333333333 & 0.6 & 0.333333 \\
\hline R5 & 1 & 0.333333333 & 0.428571429 & 0.333333333 & 1 & 0.6 \\
\hline R6 & 0.5 & 0.5 & 0.428571429 & 0.5 & 0.6 & 0.333333 \\
\hline R7 & 1 & 0.5 & 0.6 & 0.5 & 0.428571 & 0.428571 \\
\hline R8 & 0.333333333 & 0.333333333 & 0.6 & 0.333333333 & 0.428571 & 0.428571 \\
\hline R9 & 1 & 0.5 & 0.333333333 & 0.333333333 & 0.333333 & 0.428571 \\
\hline R10 & 0.5 & 0.5 & 0.6 & 0.333333333 & 0.428571 & 1 \\
\hline R11 & 1 & 0.5 & 1 & 1 & 0.6 & 1 \\
\hline R12 & 0.5 & 1 & 1 & 0.5 & 1 & 1 \\
\hline R13 & 1 & 1 & 0.6 & 0.5 & 0.6 & 0.6 \\
\hline R14 & 1 & 1 & 1 & 1 & 0.6 & 0.6 \\
\hline R15 & 0.5 & 0.5 & 0.6 & 1 & 1 & 1 \\
\hline R16 & 1 & 1 & 1 & 0.5 & 0.6 & 0.6 \\
\hline
\end{tabular}




\begin{tabular}{|c|c|c|c|c|c|c|}
\hline \multicolumn{7}{|c|}{ Table 3: Contd., } \\
\hline R18 & 1 & 1 & 0.6 & 0.333333333 & 0.428571 & 1 \\
\hline R19 & 1 & 1 & 0.428571429 & 0.333333333 & 0.333333 & 0.428571 \\
\hline R20 & 1 & 0.333333333 & 0.333333333 & 1 & 0.6 & 0.6 \\
\hline R21 & 1 & 0.5 & 0.6 & 0.5 & 1 & 0.6 \\
\hline R22 & 1 & 1 & 1 & 1 & 0.6 & 0.6 \\
\hline R23 & 1 & 1 & 0.6 & 0.5 & 0.6 & 0.6 \\
\hline R24 & 1 & 0.5 & 0.6 & 1 & 1 & 1 \\
\hline R25 & 1 & 1 & 0.6 & 0.5 & 0.428571 & 0.428571 \\
\hline
\end{tabular}

The next step is the calculation of grey relational grades (GRG) which is tabulated below in table no.4.

Table 4: Calculated Grey Relational Grades

\begin{tabular}{|c|c|c|c|c|c|c|}
\hline Criteria & C1 & C2 & C3 & C4 & C5 & C6 \\
\hline GRG & 0.826666667 & 0.74 & 0.656380952 & 0.56 & 0.606857 & 0.649524 \\
\hline
\end{tabular}

Here among the six criteria that are considered, four criteria are selected as prominent when compared to the other criteria. The criteria which are selected are C1 (Commitment to delivery schedule), C2 (An ISO 9000 certified supplier), C3 (Past supply record)\& C6 (Geographical position of the supplier).

AHP-The AHP method is also termed as Eigen-vector method. It shows that the Eigen-vector corresponding to the biggest Eigen-value in the couple manner comparisons matrix gives the relatives priorities of the factor and preserve original among the alternatives. This shows that if an alternative is proportional to another one, its Eigen-vector component is greater than that to a different one. A vector of mass obtained from the couple wise comparison matrix reflects the relevant performance of other factors. In AHP, a multiple Criteria issue is built by hierarchically by parting down a problem into minor and minor consistent pieces. The excellent alternatives usually choose by manufacturing comparisons between alternatives with respect to others. The computational process of this approach has been shown as follows:-

Step 1: Determine the aim and the results attributes and construct the hierarchy structure model.

Step 2: Comparing the relevant strength of other attributes with respect to the goal or aim.

Step 3: Make the couple wise comparison matrix by using the below table no. 5 .

Table 5: AHP Standard Preference Table

\begin{tabular}{|l|c|}
\hline \multicolumn{1}{|c|}{ Preference Level } & Numerical Value \\
\hline Equally Preferred & 1 \\
\hline Moderately Preferred & 2 \\
\hline Strongly Preferred & 3 \\
\hline Very Strongly Preferred & 4 \\
\hline Extremely Preferred & 5 \\
\hline
\end{tabular}

The weightage of the criteria are calculated and tabulated below in table 6. The pairwise comparisons are done using Saatynine-point scale. The table 6 below lists the weightage of the four chosen criteria as calculated by the AHP method. 
Table 6: Weightage of the Shortlisted Criteria Using AHP

\begin{tabular}{|c|c|}
\hline $\begin{array}{c}\text { Shortlisted } \\
\text { Criteria }\end{array}$ & Weightage \\
\hline C1 & 0.477687806 \\
\hline C2 & 0.263309545 \\
\hline C3 & 0.199513163 \\
\hline C6 & 0.059489486 \\
\hline
\end{tabular}

The shortlisted criteria and their respective weightage are further passed t on to the TOPSIS technique for the final supplier selection.

TOPSIS-The final selection of the supplier is done by using the TOPSIS technique. It is an acronym for the technique for order preference by similarity to an ideal solution. As the name suggests, the basis of this tool is to find the solution for multi-criteria problem, which is nearest to the ideal solution. A decision matrix with the values obtained from a survey conducted in a company located in Delhi-NCR as shown in table 7 below.

Table 7: Weighted Normalized Decision Matrix

\begin{tabular}{|c|c|c|c|c|}
\hline Supplier & C1 & C2 & C3 & C6 \\
\hline S1 & 0.1029056441 & 0.0472941176 & 0.0397060550 & 0.0089591867 \\
\hline S2 & 0.1029056441 & 0.0591176471 & 0.0297795413 & 0.0119455823 \\
\hline S3 & 0.0823245153 & 0.0591176471 & 0.0297795413 & 0.0119455823 \\
\hline S4 & 0.0617433865 & 0.0591176471 & 0.0496325688 & 0.0059727912 \\
\hline S5 & 0.1029056441 & 0.0354705882 & 0.0297795413 & 0.0119455823 \\
\hline S6 & 0.0823245153 & 0.0472941176 & 0.0297795413 & 0.0059727912 \\
\hline S7 & 0.1029056441 & 0.0472941176 & 0.0397060550 & 0.0089591867 \\
\hline S8 & 0.0617433865 & 0.0354705882 & 0.0397060550 & 0.0089591867 \\
\hline S9 & 0.1029056441 & 0.0472941176 & 0.0198530275 & 0.0089591867 \\
\hline S10 & 0.0823245153 & 0.0472941176 & 0.0397060550 & 0.0149319779 \\
\hline S11 & 0.1029056441 & 0.0472941176 & 0.0496325688 & 0.0149319779 \\
\hline S12 & 0.0823245153 & 0.0591176471 & 0.0496325688 & 0.0149319779 \\
\hline S13 & 0.1029056441 & 0.0591176471 & 0.0397060550 & 0.0119455823 \\
\hline S14 & 0.1029056441 & 0.0591176471 & 0.0496325688 & 0.0119455823 \\
\hline S15 & 0.0823245153 & 0.0472941176 & 0.0397060550 & 0.0149319779 \\
\hline S16 & 0.1029056441 & 0.0591176471 & 0.0496325688 & 0.0119455823 \\
\hline S17 & 0.0823245153 & 0.0591176471 & 0.0496325688 & 0.0149319779 \\
\hline S18 & 0.1029056441 & 0.0591176471 & 0.0397060550 & 0.0149319779 \\
\hline S19 & 0.1029056441 & 0.0591176471 & 0.0297795413 & 0.0089591867 \\
\hline S20 & 0.1029056441 & 0.0354705882 & 0.0198530275 & 0.0119455823 \\
\hline S21 & 0.1029056441 & 0.0472941176 & 0.0397060550 & 0.0119455823 \\
\hline S22 & 0.1029056441 & 0.0591176471 & 0.0496325688 & 0.0119455823 \\
\hline S23 & 0.1029056441 & 0.0591176471 & 0.0397060550 & 0.0119455823 \\
\hline S24 & 0.1029056441 & 0.0472941176 & 0.0397060550 & 0.0149319779 \\
\hline S25 & 0.1029056441 & 0.0591176471 & 0.0397060550 & 0.0089591867 \\
\hline
\end{tabular}


The table 8 below shows the positive ideal solution and negative ideal solutions.

Table 8: Ideal Best and Ideal Worst Solution Table

\begin{tabular}{|c|c|c|c|c|}
\hline & C1 & C2 & C3 & C6 \\
\hline Vj+ & 0.061743 & 0.035470588 & 0.019853028 & 0.014931978 \\
\hline Vj- & 0.102906 & 0.059117647 & 0.049632569 & 0.005972791 \\
\hline
\end{tabular}

The next step is to calculate the Euclidean distance from the ideal best to the ideal worst using the equations $2 \& 3$ below.

$$
\begin{aligned}
& S_{i}^{+}=\left[\sum_{j=1}^{m}\left(V_{i j}-V_{j}^{+}\right)^{2}\right]^{0.5} \\
& S_{i}^{-}=\left[\sum_{j=1}^{m}\left(V_{i j}-V_{j}^{-}\right)^{2}\right]^{0.5}
\end{aligned}
$$

Finally the performance score of all the 25 suppliers (S1, S2, S3...S25) are calculated using the equation 4 below.

$$
P_{i}=\frac{S_{i}^{-}}{S_{i}^{+}+S_{i}^{-}}
$$

The calculated values of $S_{i}^{+}, S_{i}^{-}$and the performance score i.e., $\mathrm{P}_{\mathrm{i}}$ are tabulated below in the table 9.

Table 9: Calculation of Performance Score Pi and Rank

\begin{tabular}{|c|c|c|c|c|c|}
\hline Suppliers & Si+ & Si- & Si+ + Si- & Pi & Rank \\
\hline S1 & 0.0156 & 0.04769 & 0.06329 & 0.753515563 & 8 \\
\hline S2 & 0.02089 & 0.04859 & 0.069480132 & 0.699338509 & 13 \\
\hline S3 & 0.02923 & 0.033019 & 0.062248728 & 0.530432172 & 18 \\
\hline S4 & 0.041206 & 0.039068 & 0.080273525 & 0.486680071 & 20 \\
\hline S5 & 0.031448 & 0.042448 & 0.073895821 & 0.574427895 & 16 \\
\hline S6 & 0.03107 & 0.027243 & 0.058313299 & 0.467188433 & 21 \\
\hline S7 & 0.01585 & 0.047581 & 0.063431257 & 0.750123193 & 9 \\
\hline S8 & 0.0494 & 0.020732 & 0.070132026 & 0.29561425 & 22 \\
\hline S9 & 0.03175 & 0.043242 & 0.07499157 & 0.576619078 & 15 \\
\hline S10 & 0.027243 & 0.030944 & 0.0581871 & 0.531803439 & 17 \\
\hline S11 & 0.014835 & 0.052163 & 0.066998015 & 0.778575531 & 7 \\
\hline S12 & 0.022447 & 0.043239 & 0.065685909 & 0.658267649 & 14 \\
\hline S13 & 0.011585 & 0.051542 & 0.063127292 & 0.816481912 & 5 \\
\hline S14 & 0.005973 & 0.056119 & 0.062091502 & 0.903803261 & 2 \\
\hline S15 & 0.027243 & 0.030944 & 0.0581871 & 0.531803439 & 17 \\
\hline S16 & 0.005973 & 0.056119 & 0.062091502 & 0.903803261 & 2 \\
\hline S17 & 0.022447 & 0.043239 & 0.065685909 & 0.658267649 & 14 \\
\hline S18 & 0.013372 & 0.051456 & 0.064827703 & 0.793730158 & 6 \\
\hline S19 & 0.020076 & 0.048865 & 0.068940676 & 0.708793108 & 12 \\
\hline S20 & 0.038493 & 0.041271 & 0.079763835 & 0.517412873 & 19 \\
\hline S21 & 0.016553 & 0.047299 & 0.063852383 & 0.740759568 & 10 \\
\hline S22 & 0.005973 & 0.056119 & 0.062091293 & 0.903806299 & 1 \\
\hline S23 & 0.011585 & 0.051542 & 0.063127193 & 0.816483201 & 4 \\
\hline S24 & 0.017849 & 0.047205 & 0.065054221 & 0.72562381 & 11 \\
\hline S25 & 0.010366 & 0.051801 & 0.062167207 & 0.83325592 & 3 \\
\hline
\end{tabular}

It is very much clear and evident from the table 9 above, that the "supplier 22"is the closest to the positively ideal solution and at the same time, farthest from the negative ideal solution. Hence, "Supplier 22" is the best supplier amongst the other alternatives mentioned. 


\section{CONCLUSIONS}

In the current research work, an amalgam or a hybrid of various problem-solving tools was used. Consequentially, the approach developed was a hybrid GRAPH-TOP model which aimed at solving the problem of selection the best supplier among twenty-five available suppliers. The complete problem was solved at three stages. In the beginning, the list of criteria was cut down by selecting only the four most important criteria among the six criteria. This was done using Grey Relation Analysis (GRA). Next, the shortlisted criteria were given weightage using AHP technique. Last but not least, the final supplier-selection was done using the TOPSIS method. The GRAPHTOP was used to perform an analysis on small and medium scale industries in the selection of suppliers and was applied to a small scale industry in Delhi-NCR. The GRAPH-TOP analysis shows that the "supplier 22" is closer to the positive ideal solution which is evident that it is the ideal option. The current research work also emphasizes that the MCDM GRAPH-TOP heuristics can be applied successfully in different industries too for supplier selection.

\section{REFERENCES}

1. Adalı, E., Işıl, A \& Kundakcı, K. (2016). An alternative approach based on Fuzzy PROMETHEE method for the supplier selection problem.Uncertain Supply Chain Management, 4(3), 183-194.

2. Banaeian, N., Mobli, H., Fahimnia, B., Nielsen, I. E., \& Omid, M. (2018). Green supplier selection using fuzzy group decision making methods: A case study from the agri-food industry. Computers \& Operations Research, 89, 337-347.

3. Chai, J., Liu, J. N., \& Ngai, E. W. (2013). Application of decision-making techniques in supplierselection: A systematic review of literature. Expert Systems with Applications, 40(10), 3872-3885.

4. Prasath, K. A., \& Johnson, R. D. J. Scrutiny of Machine Assignment in Various Intra-Cell Layout in Cellular Manufacturing using Automation Studios.

5. Galankashi, M. R., Helmi, S. A., \& Hashemzahi, P. (2016). Supplier selection in automobile industry: A mixed balanced scorecard-fuzzy AHP approach. Alexandria Engineering Journal, 55(1), 93-100.

6. Hamdan, S., \& Cheaitou, A. (2017). Supplier selection and order allocation with green criteria: An MCDM and multiobjective optimization approach. Computers \& Operations Research, 81, 282-304. 
